\title{
Limites e controvérsias da participação como mecanismo de gestão pública na periferia metropolitana do Rio de Janeiro
}

Limits and controversies of participation as a mechanism of public management in the periphery metropolitan of Rio de Janeiro

\author{
Andreia Pereira de Macêdo ${ }^{1}$
}

\begin{abstract}
RESUMO
Este trabalho aborda os limites das formas institucionalizadas de interação da sociedade civil com o Estado, especificamente das instâncias participativas constituídas para a deliberação de políticas públicas de âmbito local. O artigo enfoca diferentes práticas discursivas de atores coletivos inseridos diretamente em instâncias de participação multiplicadas nas últimas décadas, como os conselhos e conferências de políticas públicas, realizadas nos diferentes níveis de governo, e espaços de participação instituídos para a elaboração de Planos Diretores Participativos. A análise dos discursos produzidos em entrevistas qualitativas com informantes-chave aponta para o reconhecimento da importância da ampliação das instâncias de participação, que abriram a possibilidade de intervenção da sociedade organizada nos processos de políticas públicas, evidenciando, contudo, os seus limites no que se refere à descentralização do poder decisório e superação das assimetrias nas relações e práticas políticas locais.
\end{abstract}

Palavras-chave: Participação; gestão pública; instituições participativas; políticas públicas; Baixada Fluminense.

\begin{abstract}
This paper approaches the institutionalized forms' limits of civil society's interaction with the State, specifically the participatory instances constituted for the deliberation of local scope's public policies. The article focuses on different discursive practices of collective agents inserted directly inside participation's instances multiplied in the last decades, such as councils, and public policy conferences, accomplished in different levels of government, and spaces of participation established to elaboration of Participatory Master Plans. The speeches' analysis produced in qualitative interviews with key informants points to the importance's recognition of broadening the instances of participation, which opened the possibility of organized society's intervention in public policy processes, highlighting, however, their boundaries as regards refers to the decentralization of decision-making power, and overcoming asymmetries in local political relations and practices.
\end{abstract}

Keywords: Participation; public management; participatory institutions; public policy; Baixada Fluminense.

\footnotetext{
${ }^{1}$ Mestre em Planejamento Urbano e Regional pelo IPPUR/UFRJ. Doutora em Sociologia pela Universitat de València, com título reconhecido pelo programa de pós-graduação em Ciência Política da UFSCAR. Professora de Política pública e Planejamento urbano do Departamento de Administração e Turismo da UFRRJ. E-mail: demacedoa@hotmail.com
} 


\section{Introdução}

A participação da sociedade nos assuntos públicos passou por importantes transformações nas últimas décadas. Originalmente impulsionada pelos movimentos sociais na década de 1960, nos anos seguintes tornou-se uma questão central da teoria democrática que traduziu as demandas pela participação na tomada de decisões a partir da crescente insatisfação com as principais instituições de representação política. Nesse debate, destacam-se as críticas à democracia representativa que abriram espaço para discutir o procedimentalismo democrático como prática social e não como um método para a formação de governos (Santos; Avritzer, 2002), dando origem a propostas de novos arranjos institucionais para a participação dos cidadãos nas decisões sobre problemas que afetam mais diretamente seus interesses, abordagens chamadas de democracia participativa (PATEMAN, 1970, MACPHERSON, 1977, HELD, 1987). No campo da prática, observou-se a progressiva criação de espaços de participação em diferentes realidades para envolver a sociedade na gestão dos assuntos públicos, especialmente na área de sua comunidade, inovações institucionais que se relacionam com os processos de descentralização das funções políticas e administrativas do Estado e que também afetam as ações dos governos municipais (FONT, 2011).

No Brasil, a questão da participação tem se manifestado na agenda pública desde a década de 1980, após as mobilizações sociais por direitos e pela redemocratização, iniciada na década anterior, de luta contra o regime autoritário. A disseminação de experiências participativas no país aparece no cenário da década de 1990, após o compromisso com formas institucionalizadas de participação como alternativa para a democratização das relações entre o Estado e a sociedade. Com efeito, a promulgação da Constituição Federal de 1988 não só marcou formalmente o processo de reconstrução da democracia no país, mas estabeleceu a criação de espaços institucionais de participação nos processos relacionados com os temas de política pública, particularmente a nível local, como o Orçamento Participativo, experiência inovadora criada em 1989 pelo Partido dos Trabalhadores no município de Porto Alegre, e os Conselhos de Políticas Públicas, instituídos a partir da década de 1990 em decorrência da regulamentação de alguns artigos constitucionais. Na última década novas experiências participativas ganharam relevância na agenda do governo federal, como as Conferências, realizadas nos diferentes níveis de governo, e o Plano Diretor Participativo, instrumento de planejamento e gestão das políticas urbanas, obrigatório para os municípios com mais de 20.000 habitantes, integrantes de regiões metropolitanas e aglomerações urbanas.

A ampliação da participação da sociedade em espaços de discussão com o poder público supõe alterações nas relações entre Estado e sociedade, e nos significados da participação. As instâncias participativas não só apresentam formatos diversos e níveis variados de incidência cidadã nos processos de políticas públicas, mas estão imersos em diferentes contextos sociais e políticos. Nesse sentido, o debate acadêmico tem se centrado na qualidade democrática das experiências de participação, pois estas se multiplicaram nos últimos anos e respondem a diversas concepções de democracia participativa (PARÉS, 2009). Da mesma forma, os estudos sobre a efetividade do princípio deliberativo das instituições participativas ou formas diferenciadas de incorporação de cidadãos e associações da sociedade civil na deliberação sobre políticas (Avritzer, 2011), surgidas na democracia brasileira recente, indicam importantes desafios associados não apenas à variedade de experiências concretas de participação em espaços institucionais, mas também ao uso generalizado do termo participação em diversas práticas ditas participativas, e que parecem esconder os diferentes significados que a participação e a democracia podem assumir (LÜCHMANN, 2006). Esse debate compõe o universo mais amplo de preocupações que norteiam este trabalho, que busca contribuir para a compreensão dos diferentes significados atribuídos à participação e às formas de interação social e política nos espaços institucionalizados de participação.

A região da Baixada Fluminense, que integra o espaço da periferia metropolitana do Rio de Janeiro, foi escolhida como a base empírica do estudo porque dispõe de canais institucionais para a participação nos processos de políticas públicas, e é reconhecida tanto por um passado histórico de mobilização comunitária 
como pela importância regional em termos de população, ambiental e econômica. Essa escolha também se deve ao fato de que no contexto em que foram ampliadas as possibilidades para um debate público sobre as políticas públicas no país (2003-2010), a região conquistou um lugar privilegiado no cenário político do Rio de Janeiro, elegendo para a administração de um de seus principais municípios, uma liderança que demonstrava um compromisso com a democratização da gestão pública. A região também foi alvo de consideráveis investimentos públicos em estruturas produtivas e projetos de infraestrutura urbana e social, além das consultorias técnicas que algumas administrações municipais tiveram no processo de elaboração dos Planos Diretores Participativos, experiências que aliaram canais estáveis de participação, como o Conselho Municipal de Política Urbana, e as conferências municipais (amplamente difundidas no período), além da realização de reuniões comunitárias e a constituição de canais deliberativos para a construção dos princípios, objetivos e diretrizes da nova ferramenta de gestão de políticas urbanas locais.

O principal objetivo deste estudo é mostrar limites e contradições da participação como um mecanismo de gestão pública através da análise e interpretação de discursos produzidos por atores-chave envolvidos diretamente em processos e instâncias participativas. Para alcançar este objetivo optou-se por uma metodologia que combina práticas de observação participante e entrevistas abertas, próprias do enfoque qualitativo de investigação social, com a análise de estudos acadêmicos que caracterizam o contexto investigado.

Sobre a estrutura do trabalho, na primeira seção destaca-se o lugar que a participação dos cidadãos na gestão dos assuntos públicos ocupa nas concepções de democracia participativa e deliberativa, formuladas a partir da década de 1970, e leituras sobre as possibilidades para o aprofundamento democrático a partir de experiências participativas. Na segunda seção, identificam-se pontos comuns entre autores reconhecidos que permitem definir a participação cidadã. Em seguida, destacam-se reflexões que argumentam que a participação na vida democrática brasileira não está apenas situada em um amplo universo teórico e prático, mas seus significados estão submetidos a um processo de disputa entre projetos políticos distintos. $\mathrm{Na}$ terceira seção, busca-se uma breve aproximação ao contexto da Baixada Fluminense, apresentando aspectos relativos à formação social e urbana da região. Na quarta seção, realiza-se a análise e intepretação dos discursos produzidos pelos interlocutores da pesquisa.

\section{Participação como alternativa para uma democracia mais participativa}

Entre os principais defensores de uma maior participação na democracia representativa estão Carole Pateman (1992 [1970]) e Crawford Macpherson (2009 [1977]), segundo os quais o termo "participação" foi incorporado ao vocabulário político popular a partir dos movimentos de estudantes universitários dos anos de 1960, espalhando-se entre a classe trabalhadora na década seguinte e estendendo-se a vários governos nacionais que passaram a demonstrar interesse pelo tema incluíram o envolvimento dos cidadãos nas formulações de suas ações. Os autores não indicam que o conceito de "democracia participativa" resultou de uma resposta consciente ao chamado "elitismo democrático", enfatizando o papel dos movimentos sociais e das organizações da sociedade civil que reivindicavam a participação nas decisões políticas.

No que diz respeito à ideia de uma democracia mais participativa, Pateman (1992) destaca as teorias de Jean Jacques Rousseau e John Stuart Mill como aquelas que fornecem os postulados básicos de uma "teoria da democracia participativa" e aponta o trabalho de G.D.H. Cole como de grande importância, principalmente por introduzir essa teoria no contexto de uma sociedade moderna, de larga escala e industrializada. A autora considera que a participação permite o desenvolvimento de uma ação social e política responsável, contribuindo para a formação de uma cidadania mais comprometida com assuntos de interesse coletivo e consciente com as questões governamentais. Para alcançar a participação ampla e contínua, de modo a garantir o desenvolvimento de capacidades sociais e políticas e a aquisição de habilidades democráticas, defende que a participação seja ampliada a todos os âmbitos da sociedade, 
especialmente nas esferas do trabalho e das relações comunitárias.

Macpherson (2009) analisa a questão da participação nas democracias liberais ocidentais, destacando que parece que la esperanza de una sociedad y un sistema de gobierno más participativos va a ser algo duradero, suposto a partir da qual propõe um modelo democrático mais participativo do que o atual. Ao refletir sobre as possibilidades de uma democracia participativa, admite a dificuldade que a implantação de propostas de democracia direta em sociedades grandes e complexas pressupõe, afirmando que nestas sociedades parece evidente que, a nivel nacional, será necesario disponer de algún tipo de sistema representativo, y no de una democracia completamente directa (MACPHERSON, 2009, p. 122-123). Para o autor, embora os avanços tecnológicos permitam a participação de cidadãos comuns na discussão de questões isoladas, a formulação e execução de políticas públicas devem ser realizadas pelas instituições governamentais que têm a função de conciliar demandas incompatíveis e interesses conflitantes. Em vista disso, propõe um modelo de democracia participativa que mantêm as principais instituições representativas da democracia liberal, e encontra nos locais de trabalho e nos bairros os espaços mais apropriados para a sua realização².

Os teóricos da democracia deliberativa também reconhecem os limites da democracia liberal representativa, cujos procedimentos de agregação de preferências e vontades através do voto são insuficientes na produção de consenso sobre decisões políticas. Esses teóricos aspiram ampliar a participação dos cidadãos nas questões de interesse coletivo, mas suas abordagens estão voltadas para a deliberação pública, um princípio que, para a democracia deliberativa, implica formas de argumentação e negociações entre os participantes envolvidos em qualquer decisão política. Avritzer (2000) aponta que as ideias dos filósofos John Rawls e Jürgen Habermas desempenharam um papel central na reintrodução do elemento argumentativo no processo democrático, um quadro de referência que define a virada da teoria democrática contemporânea, no sentido de uma democracia deliberativa ${ }^{3}$.

Gutmann e Thompson (2007) enfatizam que o objetivo principal da democracia deliberativa é fornecer uma maneira mais razoável de governar para lidar com "desacordo moral na política", um desafio complexo que serve para promover a legitimidade das decisões políticas, estimular a perspectiva pública sobre questões de interesse coletivo e o respeito mútuo na tomada de decisões, e corrigir os fracassos das decisões produzidos pela compreensão incompleta em torno da realidade em geral e da questão política sobre a qual ela é deliberada ${ }^{4}$. Com relação ao alcance da democracia deliberativa, os autores defendem que a deliberação deve ser estendida às associações políticas e civis cujas decisões afetam as pessoas coletivamente. Neste sentido, observa-se que, embora se diferenciem das concepções de democracia que restringem a prática deliberativa às instituições governamentais sob o argumento de que são responsáveis pelas leis e políticas que vinculam as pessoas, os autores limitam a participação no processo deliberação pública às associações políticas e organizações da sociedade civil. Além disso, sugerem que o ideal de uma sociedade de cidadãos livres e iguais não requer que eles passem muito tempo participando na política, nem decidindo sobre todas as políticas importantes, concluindo que "a maioria dos democratas deliberativos, portanto, não insiste que os cidadãos comuns participem regularmente das deliberações públicas, e a

\footnotetext{
${ }^{2}$ Macpherson sugere a combinação de uma estrutura piramidal de conselhos locais com o sistema partidário competitivo, supondo irrealizável a implantação de um modelo sem partidos nas sociedades ocidentais atuais.

${ }^{3} \mathrm{O}$ autor esclarece que a identificação da deliberação com o momento de tomada de decisão está na base da concepção de democracia liberal representativa que se tornou hegemônica ao longo do século XX, e que a partir da década de 1970 uma interpretação alternativa do conceito de deliberação foi realizada, com base na ideia de um processo de discussão pública no qual os cidadãos e seus representantes estão envolvidos e os diferentes aspectos de uma questão política são valorizados. Também destaca que as formulações de Habermas contribuíram decisivamente para a recuperação da argumentação como um elemento-chave da deliberação democrática, a partir da elaboração do chamado "princípio do discurso" segundo o qual as normas-ações só serão válidas se encontrarem o consentimento de todos aqueles que possam ser afetados por elas.

${ }^{4}$ Os autores definem a democracia deliberativa como uma forma de governo na qual os cidadãos, livres e iguais, juntamente com seus representantes, justificam suas decisões por meio de um processo em que trocam argumentos mutuamente aceitáveis e acessíveis, com o objetivo de chegar a conclusões que são obrigatórias para todos os cidadãos no presente, no entanto, aberto a ser modificado no futuro.
} 
maioria favorece alguma forma de democracia representativa" (GUTMANN; THOMPSON, 2007, p. 46-47). Por outro lado, ainda que não constituam uma alternativa radical ao modelo da democracia representativa liberal nas sociedades ocidentais atuais, as concepções de democracia participativa e deliberativa introduzem a questão da participação e deliberação como elementos-chave para a expansão democrática nos tempos recentes. Essas abordagens oferecem contribuições relevantes para a discussão sobre o potencial democrático das formas institucionalizadas de participação, no sentido de criar possibilidades para o envolvimento de setores de cidadania nos processos decisórios e mecanismos de controle da sociedade sobre os atos dos governos, questão que será abordada na próxima seção.

\subsection{Possibilidades para o aprofundamento democrático a partir de experiências participativas}

As experiências de democracia participativa promovidas pelos governos de diferentes países, nas últimas décadas, oferecem uma variedade de canais institucionais através dos quais se dá a participação de cidadãos e organizações da sociedade civil nos processos de políticas públicas, especialmente na escala local. Estudos recentes abriram espaço para a discussão sobre o aprofundamento da democracia a partir das análises de experiências de participação para além da concepção de democracia representativa liberal.

O projeto organizado por Boaventura de Sousa Santos, que resultou na publicação da obra coletiva intitulada "Democratizar a democracia - os caminhos da democracia participativa", investiga experiências concretas em contextos determinados (diferentes países do Sul, entre eles Brasil) com o objetivo de levantar possiblidades e desafios para a "emancipação social". No texto introdutório do volume, Santos e Avritzer (2002) argumentam que as experiências de participação investigadas demonstram que a democracia representativa não constitui um simples método de formação de governos (encerrado nos sistemas eleitorais e nas garantias de acesso ao voto), mas "uma forma de organização da sociedade e da relação entre o Estado e a sociedade", dando lugar à redefinição da concepção procedimental (e elitista) da democracia. Esta redefinição se associa ao reconhecimento da relação complementar entre o procedimentalismo e a participação, ou seja, da articulação entre instituições políticas e práticas societárias, conforme observado na seção anterior.

Os autores destacam o papel dos movimentos sociais nos contextos investigados e de suas reivindicações pelo reconhecimento institucional da diversidade cultural que contribuíram para a ampliação do espaço da política e das potencialidades democráticas. Com efeito, as diferentes experiências de democracia participativa estudadas no referido projeto compartilham um elemento comum, estando intimamente ligadas aos processos de expansão e transição democrática que ocorreram a partir da década de 1970, período em que o problema da extensão da democracia aparece, pela primeira vez, para os países do Sul, entre os quais os diferentes países dos casos analisados. Esses processos se caracterizam pela inserção de novos atores na ação política, que provocou uma disputa sobre o significado da democracia, coincidindo com a luta pela redefinição de práticas societárias e identidades locais atribuídas pelos Estados coloniais ou autoritários aos que estavam submetidos. Por esta razão, os autores enfatizam a importância das experiências participativas para a redefinição da democracia como um projeto de inclusão social e política, e de inovação cultural.

No caso da sociedade brasileira, o processo de abertura democrática iniciado no final da década de 1970 incorporou novos atores sociais na cena política. O componente da participação foi introduzido na agenda pública como um resultado das demandas dos movimentos sociais pelo direito de participar da tomada de decisões locais, como é o caso do Orçamento Participativo implantado pelo Partido dos Trabalhadores em Porto Alegre no final dos anos de 1980. No entanto, como apontam Santos e Avritzer (2002), as vulnerabilidades e ambiguidades estão presentes nos processos de intensificação democrática, uma vez que tendem a ser objeto de uma disputa política, especialmente no âmbito local, que é a escala em que as experiências participativas se multiplicaram nos últimos anos. A fragilidade da participação provocada pela 
reação dos setores conservadores e interesses hegemônicos, e/ou a descaracterização da participação por via da cooptação ou da integração de grupos sociais aparecem em todos os casos analisados pelos autores.

A leitura crítica de Requena i Mora e Rodríguez Victoriano (2014) sobre as insuficiências da democracia liberal em sua forma representativa e/ou participativa contribui para o debate sobre os limites das formas institucionalizadas de participação difundidas nas últimas décadas. Com base nos aportes de Jesús Ibáñez (1997) sobre os três níveis complementares de democracia e seus alcances diferenciados de participação nas decisões políticas, os autores advertem que é o poder que inicia e regula as práticas políticas promovidas nos recentes processos participativos, com efeitos de ordem semântica e não de ordem pragmática. Os autores também afirmam que essas experiências se apoiam no protagonismo de instituições políticas cujos dispositivos formais (gerenciados para uma suposta ampliação do sistema democrático) não só têm um alcance efetivo muito limitado, mas também favorecem a legitimação de uma "democracia de baixa intensidade", através de uma participação "regulada" ou "por convite", forjada para a manutenção do poder institucional, especialmente na situação atual em que instituições políticas e governamentais estão cada vez mais servindo aos interesses dos mercados financeiros globais (REQUENA I MORA; RODRíGUEZ VICTORIANO, 2014). A partir dessas considerações, ressaltam o papel histórico dos movimentos sociais como protagonistas da mudança social, entendidos como sujeitos capazes de construir, através das lutas, um verdadeiro aprofundamento democrático ou nos termos de Santos e Avritzer (2002), uma democracia de alta intensidade. Neste sentido, no lugar de uma participação por convite, instituída com a finalidade de regular e dominar a vida social e política, os autores projetam uma participação por irrupção, não institucionalizada e protagonizada pela cidadania socialmente mobilizada, que é a que gera processos de emancipação social e práticas democráticas mais autenticas.

Cabe acrescentar que a participação é um fenômeno complexo que pode ser interpretado a partir de práticas variadas. A difusão de experiências participativas em realidades diversas dificulta a elaboração de uma definição compartilhada do termo "participação cidadã", embora a partir de uma definição mais genérica pode ser entendida como todas aquellas prácticas políticas y sociales a través de las cuales la ciudadanía pretende incidir sobre alguna dimensión de aquello que es público (PARÉS, 2009, p.17). No Brasil, a discussão sobre os desafios e limites das formas institucionalizadas de participação, criadas a partir da década de 1990, sugere que a participação está envolvida em um processo de disputa entre atores que a concebem a partir de princípios e estratégias distintos. Assim, na próxima seção serão abordadas as ambiguidades associadas às definições da participação, bem como as contradições produzidas pela difusão de experiências participativas no país.

\section{Definições e a disputa do significado da participação na democracia brasileira recente}

Há uma grande dificuldade em estabelecer uma definição de participação cidadã que perceba todos os seus significados e conotações atuais. Fazendo uma revisão por autores reconhecidos sobre o assunto, constatase que apresentam alguns pontos de convergência, principalmente aqueles que consideram o fenômeno da participação em suas dimensões mais amplas. Contudo, os elementos utilizados para tratar da participação em sua dupla dimensão (social e política) não coincidem com a chamada participação cidadã ou institucionalizada, prática política que supõe uma forma de interação entre os atores da sociedade civil e o Estado através de novos arranjos institucionais de experimentação democrática. Embora destaquem o direito e a responsabilidade dos cidadãos nas decisões sobre assuntos de interesse coletivo, autores como Bordenave (1995) e Dallari (2010) não fazem referência aos canais de participação constituídos para o envolvimento dos cidadãos nos processos de decisão política.

Tomando como característica as iniciativas que remetem às expressões de interesses sociais e que buscam intervir nas tarefas da administração pública, Cunill-Grau (1991) distingue a participação cidadã da participação social, comunitária e política, reconhecendo, entretanto, as ambiguidades subjacentes ao 
assunto em questão. Segundo a autora, a participação social refere-se aos agrupamentos de indivíduos em organizações civis para a defesa de interesses sociais, mas suas atividades não exigem uma relação entre os indivíduos que nelas interagem e as instituições estatais. Ao contrário da participação social, a participação comunitária representa uma forma de interação entre os atores da sociedade civil e do Estado, mas com um sentido estritamente assistencial, uma vez que promove a responsabilidade dos indivíduos e organizações populares em torno de problemas imediatos. Já a participação cidadã, como a autora concebe, refere-se tanto às iniciativas da cidadania destinadas a intervir em atividades governamentais quanto aos meios institucionalizados para esse fim.

Font et al. (2011) define as experiências participativas como atividades que incluem a participação de cidadãos e/ou associações no debate sobre questões locais, uma política ou assunto de interesse coletivo, e que tenham algum tipo de reconhecimento da administração municipal, ainda que esta não tenha sido quem organizou a iniciativa. Parés et al. (2009) avaliam experiências participativas que fazem parte da política institucionalizada e que, portanto, são promovidas e/ou organizados no âmbito do Estado. Mas estas também são muito variáveis atualmente, por isso os autores se baseiam em três formas institucionalizadas de participação em nível local: os espaços estáveis de participação, os processos participativos e as políticas públicas desenvolvidas de forma participativa, evidenciando o amplo espectro que engloba as diferentes maneiras de compreender e promover a participação cidadã.

\subsection{Sobre a disputa do significado da participação na democracia brasileira recente}

A questão da participação nas decisões governamentais se manifesta na agenda pública nacional na década de 1980, após as mobilizações sociais pelos direitos dos cidadãos e pela redemocratização, iniciada na década anterior, período de luta contra o regime autoritário (GOHN, 2011). Albuquerque (2004, p. 20-21) lembra que, na década de 1970, os "movimentos que se organizam como espaços de ação reivindicativa, que recusam relações subordinadas, de tutela ou de cooptação por parte do Estado, dos partidos ou de outras instituições" conseguiram multiplicar-se por todo o país, constituindo uma vasta rede de organizações populares autónomas, mobilizadas em defesa da conquista e expansão dos direitos dos cidadãos e na luta contra várias formas de discriminação. Já a década de 1980 caracterizou-se pelo que a autora chamou de "momento de inflexão dos movimentos sociais", considerando que as organizações de caráter reivindicativo e autônomo se articularam como entidades municipais, regionais e nacionais para marcar a presença de atores representativos dos setores sociais no cenário político.

A abertura de canais institucionais de participação no país resultou do processo de descentralização políticoadministrativo, um marco institucional que colaborou para a relevância do nível local nos processos de políticas públicas, e para a disseminação de práticas participativas promovidas por instituições governamentais. No entanto, o conceito de descentralização é ambíguo, sendo defendido por diferentes correntes teóricas e políticas, dentre as quais aquelas orientadas pela prescrição da reforma da administração pública, limitando-se a questionar a centralização burocrático-estatal em defesa da transferência de funções administrativas para governos e sociedades locais, e aquelas orientadas pelo compromisso com o aprofundamento democrático e que enfatizam o empoderamento de setores, grupos sociais ou espaços territoriais, apartados das decisões de políticas públicas, através de uma distribuição efetiva do poder de decisão (SOUZA, 2002).

Dagnino (2004) aponta a configuração de uma disputa político-cultural entre dois projetos políticos diferentes e antagônicos, definindo um cenário da luta pelo aprofundamento da democracia brasileira nas últimas décadas $^{5}$. Essa disputa seria principalmente discursiva, pois passa pela construção e uso de referenciais

\footnotetext{
${ }^{5}$ Trata-se de um contexto marcado, de um lado, pelo compromisso de ampliar a participação de atores da sociedade civil nos espaços de decisão política como estratégia de aprofundamento democrático, e, de outro lado, pela instalação do modelo neoliberal
} 
comuns sobre a participação nos espaços públicos instituídos, estratégia que dificulta a compreensão dos propósitos e significados das práticas participativas, produzindo o que a autora chamou de "confluência perversa". A perversidade da confluência estaria no fato de que ambos os projetos, apesar de diferentes e antagônicos em seus conteúdos e significados, requerem uma sociedade civil participativa, estratégia que produz uma aparente coincidência de propósitos que buscam confundir os atores sociais envolvidos nos canais institucionais de participação. Albuquerque (2004) concorda com essas reflexões ao afirmar que a generalização do discurso da participação a partir da década de 1990 configurou uma disputa sobre as diferentes concepções e significados assumidos pelos diferentes atores sociais e políticos em suas práticas participativas.

Em relação às dificuldades para a afirmação da participação em espaços constituídos na democracia brasileira recente, Gonh (2004) considera que a expansão da sociedade civil na década de 1990 e sua vinculação com a sociedade política contribuiu para o caráter contraditório do Estado brasileiro que, em um contexto de hegemonia neoliberal, incorporou nos discursos oficiais uma nova noção de sociedade civil: aquela associada com responsabilidade de gestão em políticas públicas. De igual modo, Lüchmann (2006) assinala que os desafios para a efetivação da participação nos processos de deliberação e decisão política no país estão associados à recente despolitização da questão social, ditada pela agenda neoliberal que, no caso das políticas públicas e sociais, promove a transferência de responsabilidades do Estado para instituições privadas e atividades relacionadas à execução de programas sociais para organizações da sociedade civil.

A emergente realidade participativa promovida no governo Lula da Silva, inaugura um novo capítulo da participação social no país. Silva (2008) destaca que, no período de 2003 a 2006, o governo federal assumiu o fortalecimento e a criação de novos espaços de participação destinados a ampliar o diálogo com movimentos sociais e organizações civis e dar voz a grupos sociais específicos. Segundo o autor, o governo federal ampliou os poderes institucionais da Secretaria Geral da Presidência da República (SGPR), que passou a dialogar com esses atores sociais, adotando como estratégia a realização das conferências nacionais e a criação de conselhos nacionais sobre direitos e políticas públicas ${ }^{6}$. Por outro lado, estudos baseados nas discussões sobre "participação, deliberação e eficácia", incluindo diversos métodos e estratégias de pesquisa, apontam que o principal desafio para a consolidação das instituições participativas no país refere-se à efetividade deliberativa e seus impactos no processo de produção de políticas públicas (AVRITZER, 2011).

A partir de 2014, a participação social perde centralidade como método de governo, com destaque para os conflitos produzidos pelo Decreto oㅜ 8.243/2014 que institui a Política e o Sistema Nacional de Participação Social (PNPS), marcando um período de retração da participação institucional. Em todo caso, como sugere Tatagiba (2005), as tendências identificadas sobre a baixa efetividade da participação nos processos de deliberação e decisões políticas devem ser exploradas, pois esses efeitos dependem de determinadas condições cuja identificação e discussão continuará a impulsionar o debate sobre os desafios da participação.

\section{A Baixada Fluminense no espaço metropolitano do Rio de Janeiro}

\footnotetext{
de Estado mínimo proposto pelo consenso de Washington. A autora observa que a eleição de Fernando Collor de Mello (PRN), em 1989, como presidente da República, marcou o início das medidas que reduzem progressivamente o papel do Estado na garantia dos direitos sociais, sendo responsabilidades estatais transferidas para a sociedade civil que, com significado redefinido, passa a ser entendida como "terceiro setor".

6 Segundo o autor, entre 2003 e 2006 foram realizadas 43 conferências (38 nacionais e 5 internacionais) com cerca de 2 mil participantes de suas etapas (nacionais, estaduais e municipais), sendo mais da metade dos participantes (55,1\%) representantes da sociedade civil, $36,6 \%$ representantes da esfera governamental e $8,3 \%$ de representantes de órgãos legislativos ou organizações internacionais que participaram como observadores.
} 
Nesta seção realiza-se uma breve aproximação ao contexto da pesquisa pontuando características relevantes para a análise dos discursos sobre as experiências participativas na região da Baixada Fluminense, que compõe a Região Metropolitana do Rio de Janeiro (RMRJ), também conhecida como Grande Rio. Os indicadores de 2010 do Instituto Brasileiro de Geografia e Estatística (IBGE) mostram que a RMRJ abriga $74,2 \%$ da população residente no estado do Rio de Janeiro, habitada por quase dezesseis milhões de pessoas. No caso da Baixada Fluminense, os dados indicam 3.333.801 habitantes, sendo a segunda região mais populosa do estado, superada apenas pela capital fluminense ${ }^{7}$.

A definição da Baixada Fluminense tem uma diversidade de representações que variam de acordo com as intenções dos atores sociais e estatais em diferentes temporalidades, algo que afeta a sua configuração geográfica, que é ampliada ou reduzida de acordo com os objetivos da análise pretendida, do projeto governamental ou das ações corporativas (ALVES, 2003; ROCHA, 2007). Há consenso em relação aos municípios de Nova Iguaçu, Duque de Caxias, Belford Roxo, São João de Meriti, Nilópolis, Mesquita, Japeri e Queimados (Figura 1).

Figura 1: A RMRJ e os municípios que integram a Baixada Fluminense

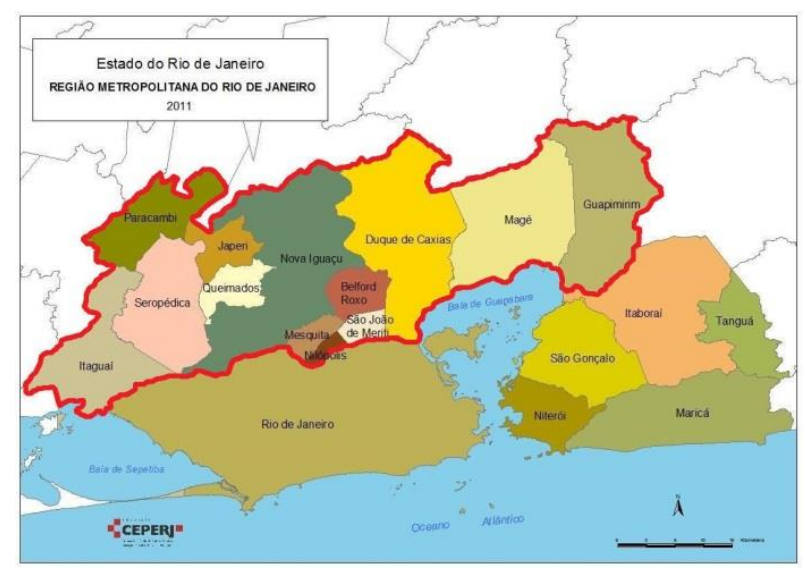

Fonte: Fundação CEPERJ, 2011.

Apesar da complexidade na definição territorial da Baixada Fluminense, dois aspectos são relevantes para a compreensão das profundas transformações em sua formação e desenvolvimento: a proximidade geográfica e a relação econômica com o município do Rio de Janeiro, que exerce a função de capital e núcleo metropolitano do estado. Esses dois aspectos mostram a "interdependência funcional" (SANTOS, 1993, p. 75) das cidades que compõem as regiões metropolitanas brasileiras estabelecidas, principalmente como resultado do acelerado processo de urbanização no país. Conforme observado por Abreu (2010) e Rocha (2007), a incorporação da Baixada Fluminense à RMRJ foi marcada por uma relação de subordinação demandada pelo crescimento das atividades produtivas e da população na cidade do Rio de Janeiro, reforçando a noção de funcionalidade para explicar a agregação da região como periferia da metrópole fluminense.

\footnotetext{
${ }^{7}$ Em estreita relação com o rápido crescimento da população urbana da Baixada Fluminense estão as iniciativas do Estado: a implantação das ferrovias; as obras de saneamento realizadas pelo Departamento Nacional de Obras e Saneamento (DNOS), cujo objetivo inicial era a criação de um cinturão agrícola para suprir a demanda interna da cidade do Rio de Janeiro; a instituição da tarifa única de trem que beneficiou os viajantes residentes nos subúrbios distantes e municípios da Baixada Fluminense; e a abertura de importantes rodovias (Avenida Brasil, em 1946, e a Rodovia Presidente Dutra, em 1951), que contribuíram para o aumento de sua acessibilidade (ABREU, 2010 [1987]).
} 
A compra de um lote de terra com condições precárias ou inexistentes de infraestrutura, equipamentos e serviços públicos essenciais configura a principal característica do processo de ocupação urbana da Baixada Fluminense, promovida para controlar a expansão das construções informais no município do Rio de Janeiro e abrigar a força de trabalho atraída pelo baixo valor da terra e pela proximidade com a capital, onde se buscavam oportunidades criadas pela industrialização. A função da região seria a de um espaço para a acomodação das massas trabalhadoras, razão pela qual seus municípios foram chamados de "cidades-dormitórios", já que a maioria de seus habitantes trabalhava na capital do Rio de Janeiro, viajando longas distâncias entre a casa e o trabalho. Barreto (2004) apresenta elementos significativos dos discursos dos moradores que produzem algum tipo de identificação com a Baixada Fluminense: a origem comum (migrantes de várias regiões, mas principalmente no Nordeste do país), a dependência econômica em relação à capital do Rio de Janeiro, o abandono público durante um longo período, a legitimidade do uso particular de violência em algumas circunstâncias e a importância do bairro e das redes de relacionamento interpessoal.

Por outro lado, estudos sobre o crescimento econômico da Baixada Fluminense mostram que a região se configura como estratégica no processo de reestruturação urbana e produtiva da metrópole do Rio de Janeiro, especialmente a partir de um conjunto de investimentos em infraestrutura e financiamento de grandes projetos. Esses investimentos estariam associados a um processo de reconfiguração do espaço metropolitano com ênfase no crescimento das cidades médias e a interiorização da economia (OLIVEIRA, 2009). Para Oliveira e Rodrigues (2009), os investimentos em projetos de infraestrutura e instalações produtivas e os empreendimentos imobiliários voltados para uma classe média com capacidade de consumo nos municípios de Nova Iguaçu e Duque de Caxias influenciaram a reorganização do espaço periférico da RMRJ, além de alterar a identidade degradada, construída em torno da violência, da pobreza, das precárias condições de vida urbana e da política clientelista ${ }^{8}$.

O escasso interesse pelas atividades políticas que caracteriza a população da Baixada Fluminense é um aspecto que merece atenção. Os indicadores referentes à associação na RMRJ na década de 1990 mostram um baixo grau de participação social, com ênfase nas diferenças entre o núcleo metropolitano e seu entorno. Enquanto na cidade do Rio de Janeiro $27 \%$ dos moradores maiores de 18 anos estava vinculado a algum tipo de organização associativa, percentual superior à média da RMRJ (24\%), a Baixada Fluminense apresentou o menor percentual de pessoas ligadas a organizações da sociedade civil (17\%), dado que reforça o pressuposto de uma população indiferente às esferas de participação (RIBEIRO; SANTOS JUNIOR, 2001). A suposta apatia cidadã revelada por indicadores de associação não estaria ligada à trajetória de uma sociedade com acúmulo de demandas e promessas públicas não cumpridas, mas a uma relação clientelista com os atores políticos e estatais.

Freire (2007) identifica uma característica singular da gramática política da Federação das Associações de Moradores de Nova Iguaçu, conhecida como $\mathrm{MAB}^{9}$. Em vez de expressar a indignação pela negligência de governos municipais sobre temas prioritários, a emoção relacionada ao sentimento de abandono, humilhação e falta de respeito é mobilizada como um recurso político não apenas para exigir a solução para os problemas locais, mas também para comover os observadores dos manifestos para que eles

\footnotetext{
${ }^{8}$ Os municípios de Nova Iguaçu e Duque de Caxias destacam-se como os núcleos centrais da Baixada Fluminense. Sem pretender esgotar a discussão sobre o recente estágio de crescimento econômico na região, associado aos investimentos de grandes projetos, vale destacar a implantação do Arco Metropolitano do Rio de Janeiro (BR493/RJ-109), uma via circular de aproximadamente 145 quilômetros de extensão, com o objetivo de conectar duas grandes estruturas produtivas: o Porto de Itaguaí e o Complexo Petroquímico do estado do Rio de Janeiro (COMPERJ), cruzando municípios da Baixada Fluminense.

${ }^{9}$ O MAB tem sua origem na década de 1970, período em que as contradições urbano-sociais em Nova Iguaçu tornaram-se mais agudas, um dos exemplos mais significativos da absorção de fluxos migratórios no Rio de Janeiro entre as décadas de 1940 e 1970. A atuação dessa organização foi reconhecida no primeiro governo do Partido dos Trabalhadores em Nova Iguaçu (2005-2008), que buscou o estreitamento dos vínculos entre o governo municipal e os atores da sociedade civil (especialmente lideranças populares incorporadas à administração) e a difusão de experiências de participação a partir da criação das Conferências da Cidade e da Campanha Nacional pelo Plano Diretor Participativo, promovida pelo Ministério das Cidades.
} 
compartilhem as demandas por mudança social. Para a autora, esse repertório emocional como gramática política tem a ver com a busca de reconhecimento e a dificuldade de ser percebido no espaço público.

As referências sugerem que as razões para o frágil engajamento cívico da população da Baixada Fluminense também devem ser buscadas na forma como o processo de ocupação urbana da região foi realizado, quase absolutamente à parte da regulação do Estado. Monteiro (2005) mostra como a origem migrante da população aliada ao abandono do poder público no processo de ocupação proletária da região contribuiu para a formação de maneiras informais na resolução dos problemas e na participação política das lideranças comunitárias, a qual não apresenta um caráter reivindicativo, mas uma forma assistencialista, como as redes de ajuda para pessoas em situações precárias. Além da rejeição à participação política como uma confirmação do modo popular de lidar com as dificuldades cotidianas às margens do poder público, o autor identifica uma percepção que vincula as instâncias do poder municipal à corrupção. Esses aspectos são relevantes para a análise realizada na próxima seção, pois não só indicam uma forma concreta de organização e reprodução da vida social, mas também uma forma de relação dos cidadãos comuns com as principais instituições políticas locais.

\section{Discursos e significados da participação em municípios da Baixada Fluminense}

Esta seção destaca diferentes maneiras de compreender a participação dos cidadãos em questões de interesse público, a partir de experiências participativas concretas. Com base nas percepções, opiniões e posicionamentos de diversos atores sociais envolvidos diretamente em instituições participativas identificam-se limites da participação nos espaços constituídos para a definição de políticas públicas, especialmente de âmbito local, e distintos significados atribuídos à participação da sociedade na gestão dos assuntos públicos.

Sobre a análise do discurso como o principal recurso metodológico, optou-se por uma abordagem da análise sociológica do discurso a partir das contribuições oferecidas fundamentalmente por Jesús Ibáñez, Alfonso Ortí, Luis Enrique Alonso, Ruiz Ruiz e Fernando Conde, vinculados à chamada Escuela Cualitativista de Madrid, corrente que tem o discurso como objeto de pesquisa social qualitativa e que, ao contrário das correntes de análise textual do discurso, busca uma aproximação ao contexto social e histórico em que os discursos são produzidos e compartilhados (CONDE, 2009).

Ruiz Ruiz (2009) define discurso como qualquer prática social segundo a qual os sujeitos dão sentido à realidade, destacando que, apesar da diversidade de formas discursivas que essa definição implica, são os discursos verbais (orais e escritos) que mais interessam à análise sociológica do discurso, pois constituem uma forma privilegiada de produção e transmissão de significados nas sociedades. Desta forma, a análise baseia-se no material empírico produzido pelas entrevistas qualitativas realizadas com diferentes atores sociais envolvidos diretamente em instâncias participativas. Em termos de atuação participativa na região da Baixada Fluminense, o município de Nova Iguaçu apresenta maior contribuição nas entrevistas realizadas, em função dos contatos com atores-chave envolvidos em diversas experiências participativas, notadamente nos conselhos e conferencias de políticas públicas, além dos espaços constituídos para a elaboração do Plano Diretor Participativo, conforme indicado no quadro 1.

Quadro 1 - Perfil dos entrevistados

\begin{tabular}{|l|l|l|l}
\hline Entrevistado* & Ocupação e trajetória nos canais de participação
\end{tabular}




\begin{tabular}{|c|c|}
\hline $\mathrm{E} 1$ & $\begin{array}{l}\text { Profissional independente. Foi membro do MAB, ocupando o cargo diretivo, e } \\
\text { representante titular do MAB no CONPURB, exercendo diferentes mandatos em } \\
\text { diferentes administrações municipais; Na última década, exerceu cargo de assessor } \\
\text { da administração de Nova Iguaçu, atuando como coordenador dos Conselhos } \\
\text { Municipais, membro da comissão executiva do Conselho Gestor do PDP, e } \\
\text { secretário executivo do CONPURB do município. }\end{array}$ \\
\hline E2 & $\begin{array}{l}\text { Bacharel em Geografia. Foi educador popular no Centro Sociopolítico da Diocesana } \\
\text { Cáritas de Nova Iguaçu, atuando como representante da entidade no CONPURB; e } \\
\text { representante da entidade local e dos moradores da Unidade de Governo Regional } \\
\text { I (URG I) no Conselho Gestor do Plano Diretor Participativo de Nova Iguaçu. }\end{array}$ \\
\hline E3 & $\begin{array}{l}\text { Profissional independente. Atua no movimento social comunitário desde } 1980 . \\
\text { Atuou na gestão do MAB, sendo diretor de política urbana. Foi representante titular } \\
\text { da organização no CONPURB e no Conselho Gestor do PDP de Nova Iguaçu; e } \\
\text { representante suplente no Conselho Municipal de Cultura e no Conselho de Defesa } \\
\text { dos Direitos Negros do município. }\end{array}$ \\
\hline E4 & $\begin{array}{l}\text { Professor de Filosofia na educação básica. Atuou no movimento social, cultural, } \\
\text { sindical e político de Belford Roxo e Nova lguaçu, nas décadas de } 1980 \text { e } 1990 \text {. } \\
\text { Desde } 2003 \text { atua como coordenador regional de uma ONG dedicada à defesa dos } \\
\text { direitos urbano-sociais em seis estados brasileiros, com forte atuação desempenho } \\
\text { na capital do Rio de Janeiro e nos municípios da Baixada Fluminense. }\end{array}$ \\
\hline E5 & $\begin{array}{l}\text { Diretor executivo de uma ONG dedicada à temática da educação ambiental há } 20 \\
\text { anos, atuando como gerente de Políticas Públicas. Representante da sociedade } \\
\text { civil no Conselho Municipal do Meio Ambiente de Nova Iguaçu exercendo diversos } \\
\text { mandatos em diferentes administrações municipais. }\end{array}$ \\
\hline E6 & $\begin{array}{l}\text { Professora de Historia na educação básica. Atua no movimento social (cultural e de } \\
\text { mulheres) de Nova Iguaçu desde a década de 1980. Na última década, exerceu } \\
\text { cargo comissionado na administração de Nova Iguaçu, atuando na Secretaria de } \\
\text { Comunicação e Participação e na Secretaria Municipal de Promoção Social. } \\
\text { Também foi membro da comissão executiva do Grupo Gestor do PDP de Nova } \\
\text { Iguaçu. }\end{array}$ \\
\hline E7 & $\begin{array}{l}\text { Técnico em Gestão Ambiental. Diretor de uma ONG dedicada à temática dos } \\
\text { conflitos socioambientais na Baixada Fluminense. Foi presidente do Fórum } \\
\text { Ecossocial da Baixada Fluminense, e representante da sociedade civil no Comitê } \\
\text { de Bacias do Rio Guandu e Guandu-Mirim. }\end{array}$ \\
\hline
\end{tabular}

* Para assegurar o anonimato e a confidencialidade, os entrevistados foram identificados com a letra inicial E.

Nas linhas a seguir identifica-se a variação de significados atribuídos à participação promovida em canais ou espaços institucionais, os quais permitem analisar as ações e interações dos atores sociais e 
governamentais, bem como limites e contradições na diversidade e complexidade das experiências participativas.

\subsection{A participação como um mecanismo de consulta popular}

Ao discorrer sobre o contexto social e político em que as condições específicas para a elaboração do Plano Diretor Participativo (PDP) de Nova Iguaçu foram estabelecidas, o entrevistado E1 destacou as diferenças entre os governos municipais em relação ao que chamou de "participação popular" no Conselho Municipal de Política Urbana (CONPURB), apresentado em seu discurso como "uma instância de participação e controle social sobre as políticas urbanas" de âmbito local. Com base nos critérios político-partidários, apontou as seguintes diferenças entre os governos municipais que conduziram a orientação do Ministério das Cidades, a partir de 2003, quanto às práticas de participação adotadas: a) a "participação consultiva sem controle social", que seria aquela praticada no CONPURB durante o governo municipal do Partido da Social Democracia Brasileira (PSDB) descrito como "liberal"; b) a "participação com o apoio do movimento popular sem poder de decisão", situação indicada para caracterizar o período de elaboração do Plano Diretor Participativo durante o governo do PT, descrito pelo entrevistado como "popular"; e c) a "participação sem qualquer controle social" como expressão dos vetos referentes à proposta elaborada pelo Grupo Gestor do Plano Diretor (de caráter deliberativo), praticados pelo governo municipal do Partido Democrático Trabalhista (PDT) no momento de instituição do Plano Diretor como lei municipal.

Em seu discurso, o entrevistado E1 dialogou com os principais referenciais da democracia representativa e deliberativa para avaliar as dimensões de uma experiência concreta de participação cidadã, a elaboração do PDP de Nova Iguaçu. Também indicou as diferenças entre os governos municipais sobre as formas institucionalizadas de participação, a partir da relação entre o governo e os setores populares, interação mediada pelos canais de participação estabelecidos, representado em seu discurso pelo o conselho de política urbana do município, o CONPURB, de caráter consultivo. Considerando as práticas participativas do entrevistado E1, observa-se que a experiência como ex-líder do principal movimento de associações de bairros do município permite a construção de um sentido de participação ligado ao envolvimento de representantes de organizações populares nos espaços criados para a deliberação de políticas públicas. Os vínculos do interlocutor com os canais e processos de participação reforçam uma percepção de que o governo exerce o papel influente na qualidade democrática das experiências participativas. Apesar de mencionar que as formas de participação variam de acordo com a agenda política dos governos locais, 0 entrevistado E1 identifica a lógica da consulta como uma característica comum de diferentes experiências participativas promovidas na última década, apontando os desafios que se colocam para uma participação efetiva ou controle social sobre as políticas públicas, uma vez que os canais consultivos permitem a voz de cidadãos sem que o poder da decisão seja compartilhado.

\subsection{A participação como uma relação entre governo e sociedade civil}

Seguindo com o diálogo sobre o contexto social e político em que ocorreu a elaboração do PDP de Nova Iguaçu, o entrevistado E2 destacou que percebeu essa iniciativa como "uma relação entre governo e atores da sociedade civil". Em seu discurso, reconheceu que, diante da necessidade formal de um processo participativo (referindo-se à obrigação legal do Plano Diretor Municipal como instrumento de planejamento e gestão das políticas urbanas de municípios brasileiros), "o governo local provocou os atores sociais", em sua opinião, "de uma maneira admirável". Por outro lado, ressaltou que "um movimento social organizado com capacidade ofensiva pode se tornar um ator político, provocando o governo a promover os processos de políticas públicas da melhor maneira possível", uma relação que produz o que definiu como "participação". O entrevistado expressou um reconhecimento da "expectativa" de uma mudança social, 
gerada pelo primeiro governo do Partido dos Trabalhadores em Nova Iguaçu, destacando uma "desilusão" causada pelo resultado do processo participativo, manifestado no longo período de tramitação e nos vetos ocorridos no momento da aprovação do projeto de lei. $O$ interlocutor estendeu a responsabilidade pelo resultado alcançado ao esvaziamento do CONPURB do qual era membro quando da elaboração do PDP.

Do ponto de vista das iniciativas do governo e dos atores da sociedade civil, o entrevistado E2 atribuiu ao primeiro a função de liderar e coordenar as experiências participativas promovidas para o envolvimento da cidadania nos processos de políticas públicas. Embora tenha qualificado como "muito limitado" o alcance das principais instituições participativas em que esteve envolvido (CONPURB e os espaços de participação estabelecidos para a elaboração do PDP de Nova Iguaçu), o discurso do entrevistado não contém referências a uma ação coletiva capaz de intervir nos processos decisórios, nem a uma alternativa de iniciativa cidadã ou dos movimentos sociais locais, sendo estes apresentados como um ator político suscetível ao poder instituído. Isso se deve aos elementos contextuais de seu discurso, que associa a atuação de lideranças da organização das associações de bairros que passaram a exercer funções públicas na administração municipal na época e a desilusão produzida pelo resultado da tramitação e instituição do instrumento de gestão das políticas urbanas locais.

O discurso produzido pelo entrevistado E3 também pode ser considerado como aquele que concebe a participação cidadã como uma forma de relação entre o governo e os atores da sociedade civil. Ao ressaltar que a "participação da sociedade civil é uma conquista permanente devido às barreiras colocadas pelos governantes", demonstrou esse modo de entender a participação na recente experiência democrática brasileira. Apesar de considerar que a criação de canais participativos resulta de uma "conquista democrática da sociedade civil organizada", o entrevistado E3 afirmou que a representação da sociedade civil nos espaços institucionais de participação não é eficaz na prática porque "o acesso a eles ainda é muito restrito". Com discurso marcado por ambivalência, o entrevistado apontou que a organização popular à qual está vinculado desde sua fundação tem representação em quase todas as instâncias de participação de Nova Iguaçu, especialmente nos conselhos de políticas públicas, alguns garantidos por lei e outros como consequência de "disputas" e "articulações" nos instâncias decisórias.

Sobre a ampliação dos canais de participação para a discussão sobre temas de políticas públicas, realizada nos vários níveis da administração (como conferências, por exemplo), o entrevistado E3 considerou a iniciativa estatal como uma possibilidade para a representação de setores organizados nos espaços constituídos, revelando a importância que atribui à representação nos canais institucionais de participação. Por outro lado, os limites da participação promovida nos espaços constituídos apareceram no discurso do entrevistado, ao relatar as dificuldades encontradas nesses espaços, com destaque para o acesso às informações sobre as políticas públicas formuladas, sugerindo o controle dos canais de participação por parte da administração municipal. Sobre este aspecto, os conselhos de políticas públicas apareceram em seu discurso como "um canal institucional do governo, que decide quando, quanto e como incentiva a participação", reforçando a ideia de uma ação empreendida para legitimar uma agenda política e institucional.

\subsection{A participação como um processo de mobilização permanente}

Entre os discursos produzidos pelos entrevistados estão aqueles que concebem a participação como um processo de mobilização social permanente. Participantes dos movimentos sociais que se multiplicaram na Baixada Fluminense na década de 1980, os entrevistados E4 e E6 apresentaram posição crítica em relação aos canais estáveis de participação (como os conselhos de políticas públicas, estabelecidos após a promulgação da Constituição de 1988), bem como em relação às novas instâncias de participação da sociedade nos processos de elaboração de políticas públicas, especialmente as conferências realizadas nos diferentes níveis de governo e os Planos Diretores Participativos. 
Ao ser perguntado sobre a importância das experiências de participação promovidas em vários níveis de decisão governamental (nacional, estadual e municipal) para engajar cidadãos e organizações sociais no processo de definição de políticas públicas, o entrevistado E4 iniciou seu discurso observando que para evitar uma resposta simplista deveria considerar o que chamou de "déficit democrático da sociedade brasileira". Em seguida destacou que o "espírito das instituições estatais" do país possui um "desprezo pelos canais de diálogo e pela população mais pobre", sendo a constante "arbitrariedade política" a principal marca de sua história, opinando que, apesar dos avanços das últimas duas décadas, "a organização social e política brasileira permanece autoritária, hierárquica e desigual". A partir dessas considerações iniciais, o entrevistado E4 reconheceu as inovações provocadas pela reconstrução democrática no país cujo arcabouço institucional é a Constituição Federal de 1988, após o surgimento de novos atores políticos no espaço público que optaram por alguns dispositivos definidos pelo entrevistado como "espaços de mediação" entre atores da sociedade civil e instituições estatais, como os conselhos gestores de políticas públicas.

O entrevistado E4 fez referência à efetividade democrática da participação, destacando que se trata de um processo complexo e longe de ser uma realidade e assumindo-se completamente cético quanto às possibilidades criadas pela expansão dos espaços institucionais de participação para a afirmação do que chamou de "democracia substantiva" no país. Apesar de reconhecer alguns dos avanços políticos e institucionais, e a criação dos marcos regulatórios relacionados às políticas urbanas, habitação social e saneamento ambiental, ressaltou que seus "impactos são minimalistas em termos de resposta às necessidades da sociedade". Sobre este aspecto, indicou um "esgotamento da participação", devido ao fato de que seus efeitos nas decisões políticas não sejam percebidos, afastando cada vez mais os cidadãos comuns dos espaços participativos e esgotando os atores sociais neles envolvidos, questão associada ao que chamou de "formalismo da democracia participativa".

A análise do discurso produzido pelo entrevistado E4 revela uma concepção de democracia como um processo resultante de múltiplas determinações e marcado por tensões e disputas entre diferentes forças sociais e políticas. Expressões como "construção" e "conflito" de um lado, e do outro, a percepção de uma sociedade civil cuja organização apresenta certa "fadiga" e "frustração", além do que identificou como "cinismo" de atores envolvidos nas instituições participativas. Enquanto as instâncias participativas foram utilizadas para caracterizar os limites da participação, os processos de mobilização social foram apresentados como elemento chave para a democratização dos espaços participativos e da própria sociedade.

Apoiada em sua experiência pessoal como uma participante de movimentos sociais locais que exerceu funções públicas durante o primeiro governo do Partido dos Trabalhadores em Nova Iguaçu, a entrevistada E6 apontou a relação de proximidade entre o governo e atores sociais locais para compreender os limites das experiências participativas impulsionadas no período. A incorporação de lideranças sociais na estrutura da administração petista foi percebida pela entrevistada E6 como uma situação que, associada ao que chamou de "desmobilização social muito forte", teve implicações para o envolvimento de atores locais nas práticas participativas promovidas durante o processo de elaboração do PDP de Nova Iguaçu. Por outro lado, ao contrário das leituras que associam as dificuldades observadas com o desempenho das lideranças sociais que exerceram funções públicas na administração, a entrevistada E6 considerou a falta de renovação de quadros nos movimentos sociais da região um ponto fundamental para a discussão sobre as limitações das experiências participativas em que ela participou como agente público. Em seu discurso, o uso de expressões como "decepção" e "desânimo" revelam o desencanto e a frustração de um ator social que apostou em um projeto político de democratização da tomada de decisões em assuntos de interesse público, mas que na prática participativa conviveu com o oposto. 


\subsection{A participação como um recurso gerencial}

Ao ser questionado sobre os canais institucionais para a participação da sociedade na gestão dos assuntos públicos, o entrevistado E5 resgatou o processo de abertura democrática brasileira, identificando inicialmente o que chamou de "participação comunitária", seguida pela formação de uma nova participação através dos "conselhos de políticas", nos quais o interlocutor tem longa experiência como representante da sociedade civil organizada, especialmente no município de Nova Iguaçu. Considerando a década de 1990, o entrevistado apontou a construção de uma "nova participação voltada para a eficiência e eficácia na gestão pública", e associada às responsabilidades dos municípios nos processos de políticas públicas adquiridas após a descentralização político-administrativa adotada no país.

Para o entrevistado E5, as mobilizações sociais da década de 1980 não deram origem a políticas públicas efetivas, pois, em sua opinião, eram "muito mais políticas do que técnicas". Já os conselhos foram apontados como canais institucionais surgidos na década de 1990, à medida que os espaços de confronto com o governo municipal, em um primeiro momento, teriam se constituído em "espaços de negociações", sendo as mudanças nas formas de participação um ponto central de seus argumentos. Apoiado no discurso da modernização da administração pública, o entrevistado apresentou como requisito para o que chamou de "participação qualificada" a realização de "cursos de formação de modo que os atores sociais incorporados nos espaços de participação possam debater e avaliar projetos inteligentes e objetivos com a gestão municipal". Sobre este aspecto, o entrevistado considerou que a população não possui "qualificação técnica" suficiente para participar de um "debate de alto nível" nos espaços constituídos para a deliberação de políticas públicas, por ele significada como uma "ferramenta para as decisões do governo, através de técnicas estrategicamente eficientes". Constata-se que o interlocutor concebe a participação como um recurso gerencial para a gestão de políticas, percebendo a administração pública como uma "empresa" que atua na "prestação de serviços" à sociedade, expressões que dialogam com a agenda neoliberal, cujo progresso produziu um novo significado da participação na gestão dos assuntos públicos.

\subsection{A participação como um instrumento de manipulação}

Assim como os demais participantes da pesquisa, o entrevistado E7 também articulou o seu discurso a partir de suas práticas participativas na região da Baixada Fluminense. Citando a "escada da participação cidadã", proposta por Sherry Arnstein (1969), para caracterizar as instituições participativas no país, o entrevistado caracterizou o que definiu como "participação manipulada", em sua opinião, "instituída para legitimar as decisões do poder estabelecido". Para o entrevistado E7, a ampliação de espaços de participação na discussão de políticas públicas resultou na "instrumentalização" dos processos decisórios do governo em exercício. Nesse sentido, a constituição e funcionamento dos espaços de participação da cidadania no planejamento e gestão de políticas públicas obedeceriam às circunstâncias e critérios essencialmente político-partidários, em suas palavras, "variam muito de acordo com o grupo político que realmente governa".

Além de relatar a sua atuação como representante da sociedade civil no Conselho de Meio Ambiente de Nova Iguaçu, o entrevistado E7 também destacou a sua participação em conferencias, espaços constituídos para o envolvimento de cidadãos e representantes de organizações civis nas deliberações diversos temas de políticas públicas. Para construir o seu discurso, destacou a experiência concreta que teve como membro do Comitê Executivo da Conferência Municipal de Saúde de Nova Iguaçu, realizada em 2009 para discutir a questão da saúde nos municípios da Baixada Fluminense. Seguindo com a construção do significado de uma participação como instrumento de manipulação, o interlocutor apontou que alguns atores da sociedade civil são estrategicamente incorporados nos canais de participação como uma garantia da prevalência de interesses, assinalando que as conferências nacionais, estaduais e municipais podem ser caracterizadas como arranjos institucionais projetados para uma "manipulação de baixo para cima das decisões do governo". 
Sobre a construção do sentido que atribui à participação um instrumento de manipulação por parte da administração pública, o discurso do entrevistado E7, assim como dos entrevistados E3 e E6, revela uma realidade constante nos canais de participação de Nova Iguaçu, principalmente no que se refere aos representantes da sociedade civil nos conselhos de políticas, que, em geral, seriam sempre os mesmos. Verifica-se que o entrevistado considera esta situação como uma chave para caracterizar a dinâmica de funcionamento dos canais estáveis de participação que, em sua opinião, são constituídos para "endossar decisões pré-acordadas" que atendam "interesses específicos e particulares".

\section{Considerações Finais}

Os discursos sobre a participação promovida nos espaços institucionais que permitem a interação entre os atores sociais e governamentais ajudaram a reconstruir e compreender experiências participativas diversas, bem como identificar a construção de diferentes significados atribuídos à participação e controle social da gestão de assuntos públicos locais, tais como: participação como mecanismo de consulta popular; participação como relação entre o governo e a sociedade civil; a participação como processo de mobilização social permanente; a participação como recurso gerencial; e a participação como um instrumento de manipulação. Esses sentidos presentes nas experiências participativas não são aleatórios, pois expressam percepções, opiniões e avaliações sobre eventos sociais e situações específicas, e não são livres de ambiguidades, pois dependem das condições sociais de sua produção e de seus produtores.

A concepção de participação como uma forma de relação entre o governo e os atores da sociedade civil é a que mais se aproxima ao que é definido como "participação cidadã". Do ponto de vista das iniciativas do governo e dos atores da sociedade civil, essa concepção atribui ao primeiro a função de liderar e coordenar as instituições participativas percebidas pela maioria dos entrevistados como "do Governo", que decide quando, quanto e como promove a participação. Já a concepção da participação como um processo de mobilização social permanente foi construída a partir da argumentação sobre a efetividade democrática da participação nas decisões políticas. Para estes sujeitos discursivos, o alcance dessa efetividade não está na ampliação das formas institucionalizadas de participação, mas na atuação dos movimentos sociais e organizações civis para a construção de políticas públicas baseadas nas reivindicações da sociedade.

Por outro lado, os atores sociais envolvidos diretamente nos espaços constituídos para a participação na discussão de políticas públicas diversas dividiram responsabilidades com os agentes estatais, ainda que em condições políticas adversas, o que permite concluir que as dificuldades apontadas estão associadas às formas de interação entre os agentes estatais e atores da sociedade implicados instituições participativas que, segundo a análise dos discursos produzidos, são relações marcadamente assimétricas. Com efeito, o trabalho de campo realizado revelou que as experiências participativas promovidas pelas autoridades locais da região da Baixada Fluminense têm limitações significativas, tais como o seu carácter específico e transitório, com efeitos para a continuidade da participação e, portanto, de sua estabilidade. Da mesma forma, os principais canais institucionais estabelecidos para a participação da sociedade civil nos processos de políticas públicas estão restritos a poucos atores coletivos, moldando um ambiente político em que o direito de participar nas decisões e questões de interesse público é bastante limitado.

\section{Referências}

ABREU, M. de. (2010). A Evolução Urbana do Rio de Janeiro. 4ª ed. Río de Janeiro: Instituto Pereira Passos, 4. ${ }^{\text {a }}$ Ed. 2. ${ }^{a}$ Reimpresión.

ALBUQUERQUE, M. do C. (2004). Participação cidadã nas políticas públicas. In: Hernmanns, K. (Org.). Participação Cidadã: novos conceitos e metodologias. Fortaleza, Expressão Gráfica, pp.15-60. 
ALONSO, L. E. (2003). La mirada cualitativa en sociología: una aproximación interpretativa. Madrid: Editorial Fundamentos.

ALVES, J. C. S.. (2003). Dos barões ao extermínio. Uma história da violência na Baixada Fluminense. Rio de Janeiro: APPH, CLIO.

AVRITZER, L. (2000). Teoria Democrática e deliberação pública. Lua Nova. Revista de Cultura e Política, São Paulo, v. 50, pp. 25-46.

(2009). Prefacio. In: Marques, A. C. S. (org. e trad.). A deliberação pública e suas dimensões sociais, políticas e comunicativas: textos fundamentais. Belo Horizonte: Auténtica, pp. 7-10.

(2011). A qualidade da Democracia e a Questão da Efetividade da Participação: Mapeando o Debate. In: Pires, R. R. (Org.). Efetividade das Instituições Participativas no Brasil: Estratégias de Avaliação. Brasília: IPEA, pp. 13-25.

BARRETO, A.. (2004). Um olhar sobre a Baixada: usos e representações sobre o poder local e seus atores. Campos, Curitiba, v. 5, n. 2, pp. 45-64.

BORDENAVE, J. E. (1995). O que é participação. 8ª reimpressão. São Paulo: Brasiliense.

CONDE, F. G. del A. (2009). Análisis sociológico del sistema de discursos. Madrid: Centro de Investigaciones Sociológicas (CIS), Cuadernos Metodológicos 43.

CUNILL-GRAU, N. (1991). Participación ciudadana. Dilemas y perspectivas para la democratización de los Estados latinoamericanos. Caracas: Centro Latinoamericano de Administración para el Desarrollo (CLAD).

DAGNINO, E. (2004). ¿Sociedade civil, participação e cidadania: de que estamos falando? In: Daniel Mato (Coord.), Políticas de ciudadanía y sociedad civil en tiempos de globalización. Caracas: FACES, Universidad Central de Venezuela, pp. 95-110.

DALLARI, D. de A. (2010). O que é participação política. 16a reimpressão. São Paulo: Brasiliense.

FONT, J. (Coord.) (2011). Democracia local en Andalucía. Experiencias participativas en los municipios andaluces. Sevilla: Fundación Pública Andaluza Centro de Estudios Andaluces.

FREIRE, J. (2007). Percepções de justiça e competências políticas em Nova Iguaçu (RJ). Ciências Sociais Unisinos, v. 43, p. 157-161.

GOHN, M. G. (2004). Empoderamento e participação da comunidade em políticas sociais. In: Saúde e Sociedade, v.13, n.2, p.20-31, maio-agosto.

. (2011). Conselhos gestores e participação sociopolítica, 4. a ed. São Paulo: Cortez Editora. 
GUTMANN, A.; THOMPSON, D. (2007). O que significa democracia deliberativa. In: Revista Brasileira de Estudos Constitucionais - RBEC. Bruno Oliveira Maciel (trad.), Pedro Buck (ed.), Belo Horizonte. Jan-mar., año 1, No. 1, pp.17-78.

HELD, D. (1991). Modelos de democracia. Alianza Editorial, Madrid.

LÜCHMANN, L. H. H. (2006). Os sentidos e desafios da participação. Ciências Sociais Unisinos, janeiroabril, año/vol. 42, número 001. Universidade do Vale do Rio dos Sinos. São Leopoldo, Brasil, pp. 19-26.

MACPHERSON, C. B. (2009). La democracia liberal y su época. Alianza Editorial, Madrid.

OLIVEIRA, A. de; RODRIGUES, A. O. (2009). Industrialização na periferia da Região Metropolitana do Rio de Janeiro: novos paradigmas para velhos problemas. Semestre Económico. Medellín, v. 12, oㅡ 24, pp. 127143.

OLIVEIRA, F. J. G. (2009). Desconcentração industrial e espaço urbano/metropolitano: análise territorial da expansão metropolitana e da formação de novos eixos econômicos produtivos no Rio de Janeiro. XIII Encontro Nacional da ANPUR. Florianópolis: Anpur, 2009. v. I. p. 1-17.

PARÉS, M. et al. (2009). Participación y calidad democrática. Evaluando las nuevas formas de democracia participativa. Barcelona, Editorial Ariel.

PATEMAN, C. (1992). Participação e teoria democrática. Rio de Janeiro: Paz e Terra.

REQUENA i MORA, M. y RODRIGUEZ VICTORIANO, J. M. (2014). Por una democracia de alta intensidad. Los movimientos sociales como portadores del cambio social. International Colloquium Epistemologies of the South: South-South, South-North and North-South global learning, Coimbra.

ROCHA, A. S. da. (2007). (Re)pensando a Baixada Fluminense em um contexto da Região Metropolitana do Rio de Janeiro: Sociedade, Território e Representação. Revista geo-paisagem [on line]. Ano 6, № 12.

RUIZ RUIZ, J. (2009). Análisis sociológico del discurso: métodos y lógicas. Forum Qualitative Sozialforschung/Forum. Qualitative Social Research, v. 10, n. 2, Art. 26.

SANTOS, M. (1993). A urbanização brasileira. São Paulo, HUCITEC.

SILVA, E. R. A. (2008). Participação Social e as Conferências Nacionais de Políticas Públicas: Reflexões Sobre os Avanços e Desafios no Período de 2003-2006. Texto para Discussão (IPEA), v. 1378, pp. 01-37.

SOUSA SANTOS, B. y AVRITZER, L. (2002). Para ampliar o cânone democrático. In: Sousa Santos, B. (Org.). Democratizar a democracia - os caminhos da democracia participativa. Rio de Janeiro: Civilização Brasileira. 
SOUZA, C.. (2002). Governos e sociedades locais em contextos de desigualdades e de descentralização. Ciência e Saúde Coletiva, v. 7, n.3, pp. 431-442.

TATAGIBA, L. (2005). Conselhos gestores de políticas públicas e democracia participativa: aprofundando o debate. Rev. Sociol. Polit. [online], n.25, pp. 209-213. SSN 1678-9873. 